\title{
COMPRANDO FEITIÇOS: AS DIFERENTES \\ FORMAS DE EXPERIMENTAR A \\ ESPIRITUALIDADE ENTRE HOMENS \\ E MULHERES NAS RELIGIÕES \\ AFRO-BRASILEIRAS
}

\author{
Nilza Menezes*
}

\begin{abstract}
RESUMO
O presente artigo, resultado parcial de pesquisa em andamento, tece algumas observações sobre as diferentes maneiras de homens e mulheres se relacionarem com os recursos mágicos propiciados nas práticas religiosas afro-brasileiras. Fizemos uso de entrevistas com sacerdotes e sacerdotisas das religiões de matriz africana, questionando acerca do atendimento religioso a partir do jogo de búzios, onde e quando, na condição de adeptos|as ou fiéis, colocam-se as questões que afligem na vida cotidiana. Pautamos o trabalho também por observações no atendimento diário e em conversas a respeito das dificuldades dos|as consulentes e fiéis, e analisamos a partir de uma perspectiva de gênero.

Palavras-chave: Gênero. Religiões Afro-brasileiras. Religião. Jogo de Búzios.

PURCHASING SPITITS: THE DIFFERENT WAYS TO EXPERIENCE SPITITUALITY BETWEEN MEN AND WOMEN IN AFRO BRAZILIAN RELIGIONS
\end{abstract}

\begin{abstract}
This article, a partial result of research in progress, makes some observations about the different ways men and women relate to the magic resources provided in Afro-Brazilian religious practices. We made use of interviews with priests and priestesses of the religions
\end{abstract}

* Doutora em Ciências da Religião pela Universidade Metodista de São Paulo (UMESP). Mestra em Ciências da Religião pela Universidade Metodista de São Paulo (UMESP). Pesquisadora do Grupo de Pesquisa em Gênero e Religião Mandrágora/NETMAL. Pesquisadora do Centro de Documentação Histórica do Poder Judiciário de Rondônia. 
of African matrix, questioning about the religious service from the game of búzios, where and when, as the adepts or faithful, are posed the issues that afflict in daily life. We also work on observations in daily attendance and conversations about the difficulties of the consultants and the faithful, and we analyze from a gender perspective. Key-words: Gender. Afro-Brazilian Religion. Religion. Búzios Game.

\title{
COMPRANDO HECHIZOS: LAS DIFERENTES FORMAS DE EXPERI- MENTAR LA ESPIRITUALIDAD ENTRE HOMBRES Y MUJERES EM LÃS RELIGIONES AFROBRASILEÑAS
}

\begin{abstract}
RESUMEN
El presente artículo, resultado parcial de investigación en curso, teje algunas observaciones sobre las diferentes maneras de hombres y mujeres relacionarse con los recursos mágicos propiciados en las prácticas religiosas afrobrasileñas. Hemos hecho uso de entrevistas con sacerdotes y sacerdotisas de las religiones de matriz africana, cuestionando sobre la atención religiosa a partir del juego de búzios, donde y cuando, en la condición de adeptos o fieles, se plantean las cuestiones que afligen en la vida cotidiana. Pautamos el trabajo también por observaciones en la atención cotidiana y en conversaciones sobre las dificultades de los consultores y fieles, y analizamos desde una perspectiva de género.
\end{abstract}

Palabras clave: Género. Religiones Afro Brasileñas. Religion. Juego de Búzios.

\section{INTRODUÇÃO}

Inicialmente, observando a categoria gênero, dentro da perspectiva que, conforme Joan Scott (1990) orienta, nos permite pensar fenômenos de maneira relacional. Buscaremos, aqui, fazer alguns comentários relacionando os sexos, como forma de pontuar distinções nas buscas religiosas de homens e mulheres, que são construídas socialmente, e refletem dentro dos espaços religiosos.

Tomaremos como base para a análise a observação de atividades de sacerdotes e sacerdotisas no jogo de búzios. O jogo de búzios, nas práticas afro-brasileiras, é um dos muitos fundamentos dentro da estrutura religiosa. É quando há entre sacerdotelisa e clientes ou fiéis o 
estabelecimento de uma relação muito íntima, tanto pela situação do sacerdote quanto da sacerdotisa, que se colocam, ou ao menos devem se colocar, da maneira mais próxima, como também dos clientes ou fiéis que colocam suas mais íntimas dificuldades para solução pelo viés de um recurso mágico. O jogo de búzios deve ter como principal função orientar os caminhos religiosos das pessoas, porém as pessoas o procuram como forma de buscar soluções para as situações das mais diversas, mas que estão de maneira geral relacionadas à saúde, família, trabalho, dinheiro, relacionamentos e sexualidade de uma forma imediatista.

A vida das pessoas se pauta nessas questões, e tudo que ocorre em suas vidas está de alguma maneira relacionado aos sustentáculos da sobrevivência e bem-estar, que são o trabalho, saúde, família e amor, porém, amor em todas as formas, que envolvem todas as formas de relacionamento do espaço público ou privado. Também é comum que o consulente busque soluções mágicas para as suas dificuldades até mesmo as inconfessáveis, como afastar pessoas indesejáveis no trabalho. Buscam solucionar questões que julgam complexas e se sentem incapazes. Entre essas incapacidades estão as dificuldades nos relacionamentos, em especial os de ordem sexual. Outra questão que se apresenta marcante nas buscas são as questões com os filhos. Principalmente quando a questão parece insolúvel para a família, em especial para a mãe, como casos de alcoolismo ou drogas. As responsabilidades familiares com os filhos ou nos relacionamentos afetivos e sexuais costumam ser um fardo para as mulheres. É uma responsabilidade socialmente estabelecida que a elas é dada, e assumida como obrigação e missão.

Nessa perspectiva, conforme aponta Emilce Dio Bleichmar em Mujeres de sienpre... mujeres del siglo XXI, "La sociedad nos lo asigna. La cultura entera nos lo recuerda” (2011, p. 13). ${ }^{1}$ Assim, as mães, esposas, avós e outras mulheres da família, educadas para o cuidado, para o perdão, nunca abandonam seus filhos, maridos, e outros parentes, nem mesmo quando eles se encontram presos, até mesmo por crimes bárbaros, ou envolvidos em drogas ou acometidos de graves doenças. E nesse sentido, também os cuidados religiosos são assumidos pelas mulheres como um ato de amor. Emilce Dio BLEICHMAR frisa que:

A sociedade nos atribui. A cultura inteira nos lembra (tradução da autora). 
Sin Duda hombres y mujeres pueden ser igualmente tributários del amor, de manera similar o diferente. Pero para muchas mujeres este tributo es particularmente pesado, grave, ya que viene a redoblar y consolidar uma estructura total de dependencia afectiva y sexual. La dependência amorosa de um hombre aparece como um hecho accidental; La dependência amorosa de uma mujer es como la naturaleza de las cosas, se inscribe perfectamente em el ordem econômico, social y cultural. ${ }^{2}$

Esse comportamento está relacionado ao papel que é dado às mulheres dentro da sociedade, de ser a responsável pelo cuidado da família, assim como, pela sua luta pautada em construções sociais de ser responsável pelo sucesso do casamento e da família. As mulheres são responsabilizadas pelo fracasso do casamento, e da harmonia familiar, e até mesmo pelo sucesso ou insucesso dos filhos. Cabe a elas cuidar da família, cuidar das pessoas da família como um sacerdócio. Elas cuidam dos homens, das crianças e das outras mulheres, e, apesar de mudanças, e de todo trabalho de conscientização que vem sendo feito, e de avanços da dependência financeira com a mulher ocupando espaços no campo do trabalho, é perceptível, em especial no caso desta pesquisa, ainda observar que embora haja um discurso público, na intimidade e em momentos de dificuldades e tensões, as velhas representações se acentuam. Ainda, conforme Emilce Dio Bleichmar (p. 14, 2011), na perspectiva da análise clínica, onde ela pauta sua análise sobre a questão da dependência amorosa como parte da natureza feminina, enquanto para o homem é um acontecimento acidental, é possível perceber que a dependência amorosa das mulheres com relação aos homens não cessou. É uma obsessão nas consciências, especialmente quando julgamos a defesa ou a negação dos homens e as desoladas queixas das mulheres.

Sem dúvida homens e mulheres podem ser igualmente responsáveis do amor, de maneira igual ou diferente. Mas para muitas mulheres esta obrigação é particularmente pesada, grave já que vem redobrar e consolidar uma estrutura global de dependência emocional e sexual. A dependência amorosa de um homem aparece como um fato acidental; a dependência amorosa de uma mulher é como a natureza das coisas, se insere perfeitamente na ordem econômica, social e cultural (2011, p. 13-14, tradução da autora). 
Assim, trazendo para o campo do atendimento religioso as questões familiares e amorosas, aparecem como funções femininas, sendo uma sobrecarga para elas que arcam com dificuldades mais complexas dos relacionamentos familiares, dos filhos, do companheiro e até outros membros da família. As mulheres geralmente são as que mais saem em busca de soluções via recursos mágicos. Isso faz romper, mesmo que momentaneamente, com preconceitos, ultrapassando barreiras da religião de pertença. Um exemplo, nesse sentido, é a procura desses recursos por mulheres, até mesmo de outras religiões, sejam católicas, pentecostais e outras denominações com filhos doentes, ou com problemas graves de drogas, com dificuldades no casamento e relacionamentos familiares. Quanto a isso, torna-se importante anotar que a procura desse público que chamamos de clientes é movida pela curiosidade ou pela compra do serviço religioso, o qual é utilizado de uma maneira comercial, como se pudesse comprar o milagre ou o feitiço.

Assim, romper a fronteira de dogmas e crenças da religião de pertença para buscar na espiritualidade o bem-estar e soluções para as dificuldades que pertencem ao mundo material pelo viés do sobrenatural é um caminho, pois as dificuldades familiares, de trabalho, de relacionamento, não dependem só da pessoa que busca, mas também do outro. Contudo, frisando que as mulheres se sentem muito mais responsáveis que os homens, o que as leva a serem maioria nessa busca, ante questões complexas da desigualdade e violência de gênero reproduzidas pelos indivíduos na sociedade.

Retomando a questão do jogo de búzios e atendimento religioso, vale frisar que é entendido como uma ferramenta de recurso mágico, como uma forma de acessar o sagrado para buscar soluções para questões de dificuldades na vida dos consulentes. E é por isso que é muito procurado por mulheres que são sobrecarregadas com dificuldades que fogem ao racional, por envolver uma carga emocional cultural muito grande que, ao não dar conta, coloca a mulher como fracassada, pois ela é responsabilizada pelos erros e fracassos dos filhos e pelo fracasso do casamento. Até mesmo quando o marido a trai, a culpa é dela, que não foi competente o suficiente, assim como os fracassos dos filhos recaem 
sobre os ombros das mulheres, que são via de regra as responsáveis pelo sucesso, saúde e até pelo caráter dos filhos.

Essa é uma grande dificuldade dos sacerdotes e sacerdotisas que possuem conhecimento sobre orixás e as funções corretas do eridilogum (jogo dos búzios), pois acabam tendo que lidar com uma clientela informada de modo equivocado, que geralmente vê as práticas religiosas de matriz africana como um caminho para o ilícito e para driblar dificuldades de maneira sobrenatural, nem sempre ética. O mau uso da religião como uma mercadoria, como um objeto de consumo, é muitas vezes propiciado também pelo comportamento de sacerdotes e sacerdotisas mal preparados, que acabam permitindo, também por interesses econômicos, que se propague a ideia equivocada sobre as funções dos recursos mágicos do jogo de búzios.

O uso dos recursos mágicos é entendido por grande parte da clientela e até mesmo por adeptos e adeptas como uma ferramenta para adquirir desejos. Se para os homens esses desejos são a potência sexual, o trabalho, dinheiro e saúde, para as mulheres os desejos estão relacionados a ter o seu homem provedor e a sua família. Essa afirmação se torna possível a partir da análise das respostas dadas pelos entrevistados.

\section{PONTUAÇÕES DA PESQUISA}

Para analisarmos de maneira mais próxima as nossas observações fizemos uso de entrevista, buscando apreender onde se localizam as diferenças entre homens e mulheres com relação aos desejos, e buscas espirituais. Essas entrevistas foram encaminhadas via e-mail a sacerdotes e sacerdotisas diversos. Enviamos aproximadamente sessenta e-mails, e recebemos seis retornos, o que significa aproximadamente $10 \%$ do campo pesquisado. Pela facilidade no meio escolhido para a abordagem, tivemos uma panorâmica interessante com pessoas de diversas regiões brasileiras. Dos questionários respondidos, dois sacerdotes e uma sacerdotisa são do Estado de São Paulo e dois sacerdotes e uma sacerdotisa do Estado de Rondônia. Os sacerdotes e sacerdotisa de São Paulo pertencem ao IFA. O sacerdote e a sacerdotisa de Rondônia pertencem ao candomblé Ketu. 
Assim, perguntamos aos nossos entrevistados: Tendo em vista o atendimento espiritual prestado na sua condição de sacerdotelisa, seja no atendimento espiritual seja no jogo de búzios, quais são as dificuldades mais presentes nas queixas das mulheres? Quais as prioridades das queixas e pedidos? Quais as distinções dos pedidos de homens e de mulheres? As respostas foram muito parecidas. Sempre anotando como prioridade das mulheres os filhos, a família e o relacionamento sexual, para os homens sempre o trabalho, o dinheiro e a saúde.

No tocante às dificuldades para o atendimento, nesse sentido, excetuando a lógica da ordem atribuída, de que as mulheres sempre buscam ajuda com relação aos filhos, geralmente sacerdotes|isas, enfrentam problemas muito similares com uma parcela considerável de frequentadores dos espaços religiosos que, na maioria das vezes, não são adeptos ou adeptas. São pessoas que procuram os serviços na condição de clientes, para comprar um feitiço. Isso ocorre, conforme se pode perceber, por razões muito subjetivas. Pode ser por falta de condições de dar conta da situação que está sendo vivenciada, mas também por entender como um serviço, geralmente, não muito ético, do qual se pode fazer uso de maneira, muitas vezes, sigilosa. Por isso, se pede muitas vezes o absurdo elou ilícito. Conforme resposta do sacerdote Babaxongo, do IFA, que também exerce a função de comerciante na cidade de São Paulo, a questão é que:

\begin{abstract}
"A maior procura de atendimento religioso, em especial na condição de cliente, são mulheres que buscam o retorno ou aproximação do namorado, ex-marido, e também vingança contra ex. querem fazer trabalho de amarração, mesmo que o jogo fale de outros assuntos, saúde, casa, trabalho, família, o assunto anterior volta à baila. Algumas desejam entender porque os relacionamentos não dão certo. São mulheres com vários filhos de pais diferentes, cujas vidas cotidianas são complexas. Homens procuram trabalho e às vezes entender 0 relacionamento familiar, as razões de mulheres que abandonam as casas deixando os filhos para o marido criar. Poucos buscam conhecimento sobre santo, (orixás) oferendas etc." (Babaxongo).
\end{abstract}

Ele ainda observa que: 


\begin{abstract}
"A verdade é que noventa por cento das pessoas que procuram o jogo são mulheres. Além de questões com filhos e outros familiares, a maioria busca soluções para relacionamento amoroso. Os clientes masculinos buscam solução profissional, negócios em geral. Alguns casos de homens que as mulheres abandonaram com os filhos e que ficaram responsáveis pelos mesmos, acabam buscando ajuda, mas geralmente, são as mulheres que buscam ajuda para problemas familiares" (Babaxongo).
\end{abstract}

No mesmo sentido para o babalorixá Osvaldo (IFA), também de São Paulo, as mulheres têm procurado muito atendimento por causa de problemas com os filhos, principalmente por causa de drogas. Também observou que os homens se preocupam mais que as mulheres com relação ao sigilo, e que buscam muitas vezes o atendimento espiritual via "entidades", o que significa que preferem o atendimento com um ser do outro mundo o que, para eles, pode ser uma maior garantia do sigilo sobre o assunto tratado.

Para a sacerdotisa Wilma de Oyá, de Porto Velho, nível superior, nação Ketu, as mulheres sempre buscam pelo viés religioso o bem-estar dos filhos, e muitas vezes outros membros da família como pai, mãe, irmãos, e ainda o relacionamento afetivo-sexual. Depois disso, a saúde e o trabalho. Já, para os homens o trabalho aparece em primeiro lugar, depois a família e a saúde. Isso reproduz, ainda de forma muito marcada a construção do homem provedor e da mulher dependente e responsável pelos cuidados com a família. No trabalho que realizamos sobre a violência de gênero nos templos de religiões de matriz africana, em pesquisa de doutorado defendida em 2012, e publicada (Nilza MENEZES, 2013) observamos essas construções dentro dos espaços das religiões de matriz africana, quando as mulheres assumem esse papel, de cuidadoras. Lembrando que elas são maioria dentro das casas de axé, que são os espaços de práticas religiosas afro-brasileiras.

Ao perguntarmos aos sacerdotes e sacerdotisas, quais as buscas das mulheres quando procuram atendimento espiritual e quando procuram atendimento do jogo de búzios? Solicitamos que fosse relacionado por ordem de interesse as questões da busca de ajuda: família, casamento, sexualidade, saúde, trabalho etc. Para os sacerdotes, o grande interes- 
se das mulheres ao buscarem o atendimento religioso está fundado nas questões familiares e sexuais. Isso, levando-se em consideração, a classe social das mulheres que procuram esse tipo de ajuda, e também da situação que vivem naquele momento. Muitas vezes, a mulher está vivendo uma situação com a qual não consegue lidar. Percebemos nas respostas que a traição dos companheiros e ou o envolvimento com homens casados são fatores de situação especial, quando a mulher não consegue administrar a situação e precisa "comprar um feitiço".

Ainda para a ialorixá Wilma de Oyá, na ordem das prioridades, as mulheres buscam atendimento por causa dos filhos, por um amor perdido, por salvar o casamento abalado, para trazer de volta a pessoa amada, para manter a unidade da família, trabalho e saúde. As maiores queixas das mulheres são assim, os problemas com os filhos e até netos, o distanciamento dos companheiros e traição. Já para os homens, a ordem dos desejos começa pelo trabalho, saúde, impotência sexual e problemas com a justiça.

Também para o babalorixá Marconi de Oxóssi, de 47 anos de idade, universitário, da nação Ketu, as mulheres buscam mais atendimento por causa dos problemas com filhos que os homens e, "que elas são mais emocionais e espirituais nas suas carências, anseios e de uma certa forma estão mais conectadas com o axé, tradução e sistematização da cultura afrodescendente no que concerne à cultura e religiosidade".

Também observa que as mulheres reclamam mais de dificuldades nos relacionamentos amorosos e sexuais que os homens. Para ele:

"O homem é mais prático na busca. Noventa por cento dos atendimentos ao sexo masculino é para questões de emprego, melhora financeira no âmbito profissional e o que sobra é pra tirar dúvidas sobre traição e relacionamentos amorosos" (Babalorixá Marconi de Oxóssi).

Essa questão, já discutida sob outras perspectivas, sempre indica que a mulher se coloca como mais responsável pelo cuidado com os filhos e mesmo como cuidadora de pessoas mais velhas e doentes da família, do marido, dos netos, enfim, a mulher é a cuidadora. Na religião não é diferente. Ela é a responsável pelo cuidado emocional e religioso. 
Essa questão também aparece de forma idêntica para os entrevistados. As mulheres sempre procuram mais o atendimento religioso pautado nas relações familiares e no que chamam de amor, que se apresenta de maneira muito complexa, pois envolve sexualidade, desejos, segurança econômica, e claro, a questão com os filhos. Nesse sentido, ainda sobre as observações de Emilce Dio Bleichmar, muito embora tenham ocorrido avanços com relação à liberdade sexual, a dependência amorosa é um paradoxo.

\section{CONSIDERAÇÕES FINAIS}

Conforme observamos, é uma investigação em andamento, porém, considerando as respostas às nossas indagações, elas indicam o que vem sendo pontuado nos estudos de gênero e religião. Existem, conforme anotado inicialmente, formas diferenciadas de lidar com o sagrado para homens e mulheres. Nesse intervalo de distinção, as violências de gênero aparecem. Conforme os entrevistados, a principal preocupação das mulheres está relacionada com os filhos e o marido, ou seja, do cuidado com a família referente à saúde e trabalho. É muito frequente a procura das mulheres por ajuda com relação ao uso de drogas por membros da família, em especial filhos e marido. Segundo os entrevistados e as entrevistadas, essa questão aparece como a principal queixa e busca das mulheres.

A segunda queixa, e que de maneira geral causa desconforto aos sacerdotes e sacerdotisas, é a busca da clientela feminina nos espaços religiosos por soluções às angústias nos relacionamentos de ordem sexual. A observação é quase sempre a mesma, por parte dos sacerdotes, as mulheres buscam um homem, ter ou manter o seu homem provedor, ter um homem para chamar de seu, e geralmente é um homem com outras relações, o que requer, portanto, uma ajuda sobrenatural: um feitiço. São relacionamentos conturbados com homens casados, onde as mulheres acabam entrando em uma "guerra", buscando resolver problemas relacionados às questões de interpretações sociais, onde a ambiguidade da liberdade sexual não acompanha os desejos. A complexidade gerada é causadora de muito sofrimento, o que estabelece 
entre as mulheres um campo competitivo, onde o homem é objeto de desejo e disputa.

Aos homens cabe, ainda, muito mais o papel de provedor. Nesse sentido, suas buscas são de trabalho, dinheiro para manter sua condição. Isso não quer dizer que não tenha dificuldades com a saúde, a família e a sexualidade, porém, não é o que aparece em primeiro plano, pois para ele se tiver dinheiro terá como adquirir sexualidade, família e bem-estar social.

Apesar de terem os sacerdotes e sacerdotisas consciência do equívoco que são tratados os recursos mágicos das práticas afro-brasileiras, acabam permitindo a reprodução na medida em que cuidam, orientam e não tecem juízo de valor sobre os pedidos. Isso é gerador da reprodução de entendimento errôneo sobre as religiões de matriz africana, por falta de uma filosofia clara sobre as mesmas que são pautadas em práticas que permitem o uso dentro do imaginário próprio de cada um. As práticas afro-brasileiras permitem serem utilizadas como uma prestação de serviço religioso, o que cria uma simbiose entre o prestador de serviço e o usuário, pautada em lucros. O encontro da falta de conhecimento e ética do cliente e do interesse do prestador de serviços acaba por gerar a reprodução dos entendimentos que resultam numa imagem negativa das religiões de matriz africana. Uma religião prestadora de serviços ilícitos que pode ser usada, mas que não gera compromisso por parte do cliente que estabelece uma relação na base do "estou pagando" para ter algo que quer, adquirindo um desejo momentâneo que pode ser descartado depois, assim como, o compromisso religioso estabelecido pelo desejo poderá ser descartado por não ser mais interessante.

Nas nossas observações e pelo resultado das entrevistas, percebemos que o fato de serem procurados como prestadores de serviços mágicos, um vendedor de desejos, incomoda aos sacerdotes e sacerdotisas que possuem outros entendimentos. Para Babaxongo, isso é um entrave no atendimento que deveria ajudar a pessoa a melhorar como ser humano, e, que na verdade aflora seus desejos antiéticos de desejar o emprego do outro, o carro do outro, o homem da outra.

Retomando a questão do jogo de búzios, que é procurado pelas pessoas, e é entendido unicamente como meio divinatório que serve 
para saber se vai conseguir ou não o que deseja, seja trabalho, homem etc., isso causa conflito para os profissionais sérios da religião, que possuem conhecimento sobre a verdadeira função do jogo, como um oráculo para orientações espirituais.

A tarefa de conscientização torna-se difícil, pois ela é um longo processo de desconstrução, e se pode perceber que mesmo entre adeptos e adeptas com iniciações e grande tempo de participação nos rituais, o equívoco se apresenta. Muitos fazem as iniciações aguardando milagres externos para a vida afetiva, trabalho, família, sem que tenham que fazer outros esforços para isso. Quando fracassam, culpam os sacerdotes, alegam erros nas feituras, pela dificuldade em mudar suas vidas, seus posicionamentos e principalmente seu caráter. As mulheres acabam por buscar o acesso a esse universo de comprar feitiços, em razão da sua responsabilidade para solucionar problemas das mais variadas ordens, e que nem sempre é possível pelo viés da razão. Isso significa que, além da busca da liberaçãollibertação das mulheres pelo viés econômico e político, onde necessitam alcançar independência econômica e igualdade de oportunidades, também é preciso ter em consideração as construções sócio-históricos da condição feminina que, geralmente, levam a mulher para o campo do existencialismo, que é fator preponderante para a reprodução de ideias cristalizadas sobre maternidade e relacionamento afetivo. A natureza feminina como doce, boa, assim como a maternidade como dom, sustentadas pela palavra amor, fazem que as mulheres sofram por esse amor, ao qual estão fadadas a sentir.

Quanto à necessidade das mulheres em comprar os feitiços se dá em razão da falta de conhecimento religioso e condições objetivas para resolver as dificuldades cotidianas nos relacionamentos, quando os filhos e maridos recaem sobre sua responsabilidade. Por sua vez, alguns sacerdotes, também desinformados, ou formatados em práticas aprendidas por esse viés, de "vender feitiços", e ainda em decorrência de ser essa prática uma maneira de ganhar dinheiro, justificando o desejo e dificuldade do cliente|consulente, acabam por proliferar essas práticas. Isso faz que o serviço seja ofertado e adquirido com todos os riscos que isso implica, e até mesmo sob um discurso de generosidade, ou de que está ali para ajudar nas dificuldades e não para julgar. 
Vale uma observação: embora o pedido seja ilícito, nos casos de pedidos de homens para derrubar o chefe, ocupar cargos de outros, e das mulheres em ficar com o marido de outra, enganar o seu marido etc., e embora haja conversas sobre a possível exploração por parte de sacerdotes que vendem algo subjetivo, o feitiço, cuja garantia é o trabalho de um ser espiritual, observamos que raramente ocorrem denúncias formais, pois tanto o comprador quanto o vendedor sabem da ilicitude do negócio.

Foi possível observar que, independentemente da região do país, as respostas possuem um fio condutor, que mostram que, geralmente, existe por parte de clientes o desejo de conquistar, sem muito esforço pessoal, amor, sucesso, dinheiro e bem-estar. Isso ainda resulta em questões muito complexas, por exemplo, se a pessoa alcança o desejo pode acreditar num poder "diabólico" que o movimentou, ou se não alcança, critica como tendo sido explorada, enganada e manipulada seja pelo sacerdote, seja pelo "demônio" causador dos fracassos.

No campo mágico religioso, torna-se possível perceber que, na intimidade, conforme consideram Celia Amorós e Ana de Miguel (2005, p. 75), apesar das conquistas legais nas sociedades democráticas, a situação comparativa entre os sexos continua sem grandes mudanças, e que ainda há um desafio, que é o de encontrar respostas aos mecanismos de reprodução da desigualdade. Apesar das conquistas, observa-se o que é anotado por Raewyn Connell, há uma grande resistência dos homens e meninos para as mudanças de gênero, o que estaria relacionado com a ameaça à identidade (2016, p. 101).

Vale dizer que, nos espaços religiosos, essas ambiguidades entre questões legais e intimidade se reforçam por permitirem fugas para situações que são difíceis para ultrapassar, permitindo a manutenção de situações transferidas do social para o sobrenatural.

\section{REFERÊNCIAS}

AMORÓS, Celia. MIGUEL, Ana de. Teoria Feminista: de la ilustración a la globalización. Vol. 01. Madrid-España: Minerva Ediciones, 2005. 
BLEICHMAR, Emilce Dio. Mujeres de siempre... mujeres del siglo XXI. In: Mujeres tratando a mujeres com mirada de género. (Cordinadora: Emilce Dio Bleichmar) Barcelona: Octaedro, 2011.

CONNELL, Raewyn. Gênero em termos reais (tradução Marilia Moschkovich). São Paulo: Versos, 2016.

MENEZES, Nilza. A violência de gênero nas religiões afro brasileiras. UFPB, João Pessoa, 2013.

SCOTT, Joan. Gênero: uma categoria útil para a análise histórica. In: Educação e Realidade, 16 (2): 5-22, Porto Alegre, jul./dez., 1990.

Submetido em: 16-5-2018

Aceito em: 18-6-2018 